\title{
Does central bank communication really lead to better forecasts of policy decisions? New evidence based on a Taylor rule model for the ECB
}

\author{
Jan-Egbert Sturm • Jakob De Haan
}

Published online: 6 November 2010

(C) The Author(s) 2010. This article is published with open access at Springerlink.com

\begin{abstract}
Nowadays, it is widely believed that greater disclosure and clarity over policy may lead to greater predictability of central bank actions. We examine whether communication by the European Central Bank (ECB) adds information compared to the information provided by a Taylor rule model in which real-time expected inflation and output growth are used. We use five indicators of ECB communication that are all based on the ECB President's introductory statement at the press conference following an ECB policy meeting. Our results suggest that even though the indicators are sometimes quite different from one another, they add information that helps predict the next policy decision of the ECB. Furthermore, also when the interbank rate is included in our Taylor rule model, the ECB communication indicators remain significant.
\end{abstract}

Keywords ECB $\cdot$ Central bank - Communication - Taylor rule

JEL classification E52 $\cdot$ E53 $\cdot$ E3

\footnotetext{
J.-E. Sturm · J. De Haan

KOF Swiss Economic Institute, ETH Zurich, Zurich, Switzerland

J. De Haan

De Nederlandsche Bank (DNB), Amsterdam, The Netherlands

J.-E. Sturm · J. De Haan

CESifo Munich, Munich, Germany

J. De Haan $(\bowtie)$

Faculty of Economics and Business, University of Groningen,

PO Box 800, 9700 AV Groningen, The Netherlands

e-mail: jakob.de.haan@rug.nl
} 


\section{Introduction}

Since monetary policy is increasingly becoming the art of managing expectations, communication has developed into a key instrument in the central bankers' toolbox. Greater disclosure and clarity over policy may lead to greater predictability of central bank actions, which, in turn, reduces uncertainty in financial markets. Nowadays, there is a strongly held belief among central bankers that a high degree of predictability is important. According to Poole (2001, p. 9), "The presumption must be that market participants make more efficient decisions ... when markets can correctly predict central bank actions." Communication may also enhance the effectiveness of monetary policy.

The extent to which central bank communication has been successful is very much an empirical issue. Therefore, it is no surprise that the empirical literature on central bank communication has seen major developments in recent years. ${ }^{1}$ Many of these studies refer to the communication policy of the European Central Bank (ECB). There is substantive evidence that ECB communication moves financial markets in the intended direction (see, for instance, Ehrmann and Fratzscher 2007; Musard-Gies 2006; Brand et al. 2006). There is also a consensus that ECB communication increases the predictability of interest decisions by the ECB (De Haan 2008). The ECB tries to prepare markets for upcoming interest rate decisions using its communication policy. So, ECB communication contains some forward guidance and may have predictive power. Even in the absence of forward guidance, central bank communication variables can meaningfully enter a Taylor (1993) rule model: with only inflation and output included, a Taylor rule model is very likely to be mis-specified, since central banks typically base their interest rate decisions on many more economic variables. If the ECB President gives the overall assessment of the economic situation based on all the variables that the ECB looks at, central bank communication might be a very useful way to summarise this information content in a very parsimonious fashion.

However, there is disagreement in the literature about the extent to which ECB communication adds information compared to the information contained by macroeconomic variables that are typically included in a Taylor rule model. For instance, whereas Heinemann and Ullrich (2007) and Rosa and Verga (2007) conclude that communication adds information not provided by these macroeconomic variables, Jansen and De Haan (2009) find that straightforward Taylor rule models outperform models using only communication indicators.

The purpose of this paper is to re-examine to what extent ECB communication adds information compared to the information provided by a Taylor rule model in which expected inflation and output growth are used when forecasting upcoming interest rate decisions. There are some important differences between our study and previous research. First, Heinemann and Ullrich (2007) and Rosa and Verga (2007) estimated backward-looking Taylor rule specifications. However, as Svensson (2003) has shown, even if the ultimate objective of monetary policy is to stabilize inflation and output, a simple Taylor rule will not be optimal in a reasonable macroeconomic model.

\footnotetext{
${ }^{1}$ See Blinder et al. (2008) for an extensive survey. See also Ehrmann and Fratzscher (2009).
} 
Interest rate changes affect inflation and output with a sizable lag. Therefore, monetary policy has to be forward-looking. Some recent studies suggest that the use of expected inflation and output growth lead to very different results than backward-looking Taylor rule models for the ECB (Sauer and Sturm 2007; Gorter et al. 2008). ${ }^{2}$ For instance, Gorter et al. (2008) report that in their backward-looking Taylor model the Taylor principle does not hold, in contrast to the Taylor model with expected inflation and output growth. So the findings of Heinemann and Ullrich (2007) and Rosa and Verga (2007) may just reflect their use of a potentially mis-specified Taylor rule model. Jansen and De Haan (2009) employed a similar forward-looking Taylor rule model as used in the present paper and conclude that their communication indicator does not increase the fit of the model. ${ }^{3}$

Second, all previous papers use just one indicator of ECB communication. Whereas Heinemann and Ullrich (2007) and Rosa and Verga (2007) use communication indicators that are based on the introductory statement of the ECB's President at the press conference following the ECB policy meeting, Jansen and De Haan (2009) employ an indicator based on Bloomberg news reports. We will show that even if various communication indicators are based on the same information, i.e. the speech of the ECB's President after the policy meeting, they give very different signals about the direction of the ECB monetary policy. In order to test to what extent results are sensitive to the choice of a particular indicator, we employ five different indicators of ECB communication that are all based on the ECB President's introductory statement at the press conference following an ECB policy meeting. Apart from the indicators of Heinemann and Ullrich (2007) and an updated version of the index of Rosa and Verga (2007), we employ the aggregate index of Berger et al. (2010), the KOF Monetary Policy Communicator (MPC) as published by the KOF Swiss Economic Institute, and the indicator of Ullrich (2008).

Our main finding is that ECB communication turns out to be significant in our Taylor rule model. In other words, it is worthwhile for financial market participants to read the ECB President's lips, as this adds information about upcoming interest rate decisions that is not provided by expected inflation and expected output growth. This conclusion holds for most communication indicators. We include the interbank rate to control for financial markets forecast of future ECB monetary policy moves (e.g. Bernoth and von Hagen 2004). Even in this specification, the ECB communication indicators remain significant. Using Brier scores and the ranked probability scores, we conclude that Taylor rule models that include ECB communication indicators outperform models without those indicators in terms of their out-of-sample forecasting abilities.

The paper is organised as follows. Section 2 outlines the model, while Sect. 3 describes the data. Section 4 presents the results and Sect. 5 offers the conclusions.

\footnotetext{
2 In some specifications of his policy reaction function for the ECB, also Gerlach (2007) uses expected inflation and expected output growth. His estimates differ substantially from those of Sauer and Sturm (2007) and Gorter et al. (2008). Gerlach concludes, for instance, that inflation is not significant in his Taylor rule model for the ECB.

3 Another possible reason why Jansen and De Haan (2009) come to different conclusions than Heinemann and Ullrich (2007) and Rosa and Verga (2007) is that their sample period refers to 1999-2002 only. They also use a different communication variable.
} 


\section{The model}

According to the Taylor rule, in setting its policy instrument $\left(i_{t}\right)$ the central bank should react to deviations of inflation $\left(\pi_{t}\right)$ from its target $\left(\pi^{*}\right)$ and to deviations of output $\left(y_{t}\right)$ from potential $\left(y^{*}\right)$ :

$$
i_{t}=(r *+\pi *)+\beta\left(\pi_{t}-\pi *\right)+\gamma\left(y_{t}-y *\right),
$$

where $r^{*}$ is the neutral real interest rate, and $\gamma>0, \beta>1 .^{4}$ As the ECB is known not to focus on the output gap (Gerlach 2007), probably in view of the difficulty to measure it in a real time situation, we estimate a Taylor rule using output growth. Walsh (2004) and Gerberding et al. (2005) argue that such a rule performs well in the presence of imperfect information. We assume a constant potential growth rate and include $\Delta\left(y_{t}-y^{*}\right)$ instead of $\left(y_{t}-y^{*}\right)$ :

$$
i_{t}=(r *+\pi *)+\beta\left(\pi_{t}-\pi *\right)+\gamma\left(\Delta y_{t}-\Delta y *\right) .
$$

Most previous studies that estimated a Taylor rule for the ECB used data for the actual (ex-post) inflation rate and the output gap. Svensson (2003) has shown that even if the ultimate objective of monetary policy is to stabilize inflation and output, a simple Taylor rule will not be optimal in a reasonable macroeconomic model. Because interest rate changes affect inflation and output with a sizable lag, monetary policy has to be forward-looking. Sauer and Sturm (2007) and Gorter et al. (2008) therefore estimate Taylor rules using forward-looking (and real-time) data. Similarly, our model is defined as:

$$
i_{t}=(r *+\pi *)+\beta\left(E_{t} \pi_{t+12}-\pi *\right)+\gamma\left(E_{t} \Delta y_{t+12}-\Delta y *\right),
$$

where $E_{t}$ is the expectations operator and the time index now refers to months. ${ }^{5}$

Generally, central banks adjust interest rates in small steps to the target rate $i_{t}^{T}$ (often referred to as interest rate smoothing), so that we can write:

$$
i_{t}^{T}=(r *+\pi *)+\beta\left(E_{t} \pi_{t+12}-\pi *\right)+\gamma\left(E_{t} \Delta y_{t+12}-\Delta y *\right) .
$$

The actual interest rate, $i_{t}$, adjusts only slowly to this target, i.e.:

$$
i_{t}=\rho i_{t-1}+(1-\rho) i_{t}^{T}+v_{t}
$$

or

$$
\Delta i_{t}=(1-\rho)\left(i_{t}^{T}-i_{t-1}\right)+v_{t},
$$

where $\rho$ denotes the smoothing parameter and $v_{t}=\delta v_{t-1}+\varepsilon_{t}$. The observed inertia may also be explained by serially correlated error terms in the policy rule (omitted shocks like financial crises) (see Rudebusch 2002).

\footnotetext{
4 According to the "Taylor principle", $\beta>1$, i.e. if inflation increases the nominal interest rate must increase more $(\Delta i>\Delta \pi)$ in order to raise the real rate.

5 Data restrictions force us to use a lead of 12 months.
} 


\section{Data}

Our data refer to the euro area over the period 1999-2007, although some ECB communication indicators are only available for a shorter period. Our dependent variable is the Main Refinancing Rate (MRR) as determined by the ECB Governing Council (source: ECB). Real-time expected inflation and output growth time series have been constructed from Consensus Economics forecasts. These forecasts are used as a proxy for the ECB's expectations of inflation and output growth. The Consensus data are unique, not revised and, consequently, not subject to the real-time critique of Orphanides (2001). ${ }^{6}$ Every month, major banks and forecast institutes in the EMUcountries give their forecasts for the near future, i.e. the current and the next year. Euro area expected inflation and gross domestic product (GDP) growth series are constructed from these forecasts for all euro area countries except Luxembourg. ${ }^{7}$ As Consensus Economics did not collect euro area forecasts before December 2002, we use country-specific forecasts, which are weighted by their share of GDP in the euro area GDP.

Figure 1 shows the MRR and expected inflation and expected output growth. In addition, the one-month Interbank Rate (IBR) is shown (source: ECB). As part of our robustness analysis, the difference between the MRR and the IBR is included as an additional control variable. Not surprisingly, both interest rates move closely together. Expected output growth and the MRR also move together to some extent, while the co-movement of expected inflation and the MRR seems to be limited since expected inflation hovers around the ECB's medium term objective of an inflation rate below, but close to $2 \%$.

Various approaches have been developed in the literature to measure (the effects of) central bank communication (see Blinder et al. 2008 for more details). Starting with Kohn and Sack (2004), various studies have examined the effects of central bank communication events on the volatility of financial variables. The basic idea is that, if communication affects the returns on financial assets, the volatility of these returns should be higher on days of central bank communication, ceteris paribus, because the signals contain "news." Focusing on volatility makes it unnecessary to assign a direction to each statement. The most important weakness of this approach is that it cannot assess whether markets moved in the "right" direction. In other words, the Kohn and Sack approach may establish that central bank communication creates news, but it is unable to determine whether it reduces noise.

In another approach, communication is quantified in order to assess both the direction and magnitude of its effects on asset prices - and thus to determine to what extent communication has its intended effects. Communication must be classified according to their content and/or likely intention, and then coded on a numerical

\footnotetext{
${ }^{6}$ Orphanides (2001) has shown that the use of real-time instead of ex post data leads to very different estimated coefficients in Taylor rule models for the Federal Reserve.

7 To convert the reported growth rates into monthly moving figures, we take as the 12-month forecast the weighted average of the forecast for the current and the following year, where the weights are $x / 12$ for the $x$ remaining months in the current year and $(12-x) / 12$ for the following year's forecast. As the survey is conducted at the beginning of each month, we consider the current month to belong to the remaining months in the current year.
} 


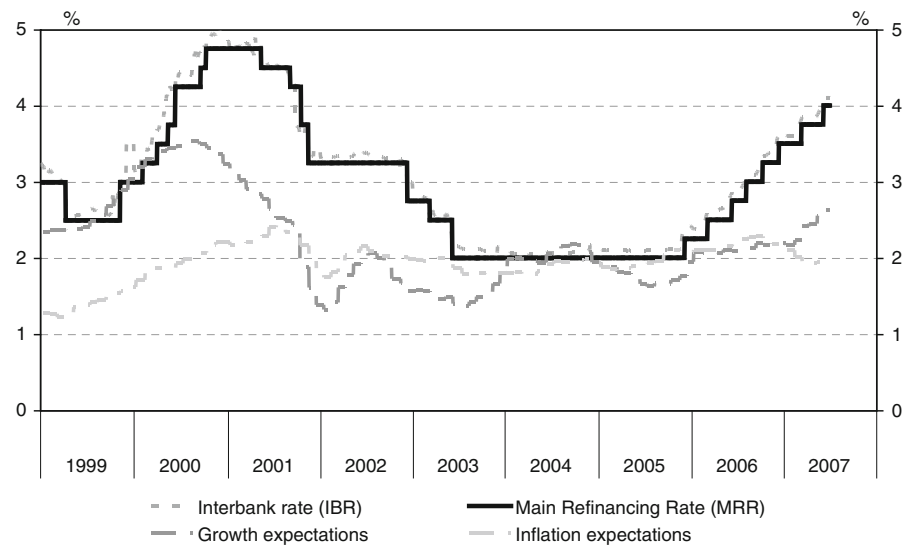

Fig. 1 Economic variables included in the Taylor rule model. Notes The main refinancing rate and the 1-month interbank money market rate stem from the ECB. Growth and inflation expectations are derived from the consensus forecasts as published by Consensus Economics Inc

scale. Negative (positive) values are assigned to communication that is perceived as dovish (hawkish), and zero to those that appear to be neutral. Whereas some researchers restrict the coding to directional indications by using a scale between -1 and +1 (e.g. Ehrmann and Fratzscher 2007), others assign a finer grid that is at least suggestive of magnitude, e.g. by coding statements on a scale from -3 to +3 (e.g. Berger et al. 2010). The most important weakness of the second approach is that it is necessarily subjective, and there may be misclassifications. Indeed, various indicators that are based on the same information set differ quite substantially from one another, as we will show.

The ECB's most important communication device is the President's introductory statement at the monthly press conference in which he reports on the decisions taken by the ECB's Governing Council (De Haan 2008). Following meetings of the Council, which typically take place on the first Thursday of each month, the ECB announces the monetary policy decisions at 13:45 (CET). Some 45 min later, at around 14:30, the ECB President and Vice-President hold a press conference that comprises two elements: a prepared introductory statement that contains the background considerations for the monetary policy decision, and a Questions \& Answers (Q\&A) part during which the President and the Vice-President are available to answer questions by the attending journalists. The introductory statement is understood to reflect the position and views of the Council, agreed upon on a word-by-word basis by its members.

In our analysis we include five indicators that are all based on the introductory statement by the ECB President, namely an updated version of the index of Rosa and Verga (2007), ${ }^{8}$ the aggregate index of Berger et al. (2010), the index of Heinemann and Ullrich (2007), the KOF Monetary Policy Communicator (MPC) as

\footnotetext{
8 The original Rosa and Verga index ends in 2004. Carlo Rosa kindly provided an updated version of their indicator which allows us to also use more recent years.
} 
published by the KOF Swiss Economic Institute and used by Conrad and Lamla (2007), ${ }^{9}$ and the indicator of Ullrich (2008). ${ }^{10}$ All data used in the present paper are available. $^{11}$

Different from the other indicators, the KOF MPC is based on the interpretation of the introductory statements by the ECB President by Media Tenor, a media research institute. Media analysts read the text of the introductory statement of the monthly press conference sentence by sentence and code them. The coding is aggregated by the KOF Swiss Economic Institute into an index by taking balances of the statements that reveal that the ECB sees upside risks to future price stability and statements that reveal that the ECB sees downside risks to future price stability, relative to all statements about future price stability (including neutral ones). Hence, in contrast to the other communication indicators we consider, it only takes forward-looking statements into account. By construction, the values of the KOF MPC are restricted to be in the range of minus one to plus one. The larger a positive (negative) value of the KOF MPC, the stronger the ECB communicated that there are upside (downside) risks for future price stability.

Figure 2 shows the various ECB communication indicators that we use, while Table 1 shows the correlation of the various indicators. It becomes clear that the indicators are sometimes quite different from one another. Whereas the correlation coefficients amongst the first three indicators compiled by economists are around 0.8 , their correlation with the KOF MPC is more modest. ${ }^{12}$

The next step in our analysis is to estimate a forward-looking Taylor rule model for the ECB and to augment this model with the ECB communication indicators outlined above. ${ }^{13}$ As we start with daily information, we need to decide at which moment in time to forecast the next interest rate decision. Two moments in time appear natural: (i) at the day of and directly after the previous policy decision, and (ii) the day the new Consensus forecasts are released (see Fig. 3). At that day, there is new information on expected inflation and expected growth. We have decided to focus on the second option as it will be the hardest test for the ECB communication indicators to have any affect at all. After all, in this set-up information provided by the ECB communication is already captured in the Consensus forecasts and the interbank rate.

\footnotetext{
9 Available at: http://www.kof.ethz.ch/communicator.

${ }^{10}$ Katrin Ullrich kindly provided her indicator. Other ECB communication indicators (like that of Jansen and De Haan 2009) are based on other communication devices and are therefore not included. The index of Musard-Gies (2006) is only available for a short period and is therefore not included.

11 See www.kof.ethz.ch/wp236.

${ }^{12}$ We have also applied a principal components analysis on the various indicators. The first principal component explains almost $68 \%$ of the variance of the individual indicators. In line with Table 1 , the correlation of the KOF MPC with the principal component is only 0.50 .

13 Using a different methodology that we cannot employ due to lack of sufficient variability of our interest rate data, Kim et al. (2008) also estimate various Taylor rule models in their analysis of the predictability of interest rate decisions by the Bank of England. These authors do not include central bank communication in their model.
} 


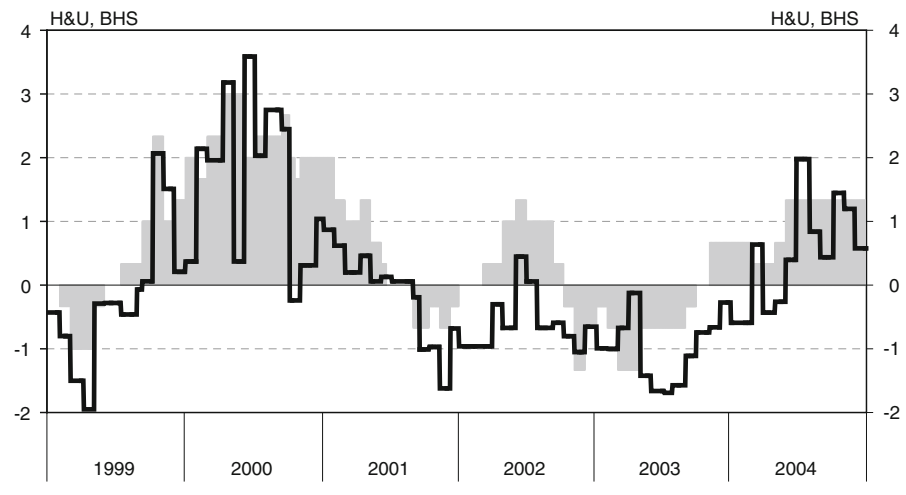

BHS $-\mathrm{H} \& \mathrm{U}$

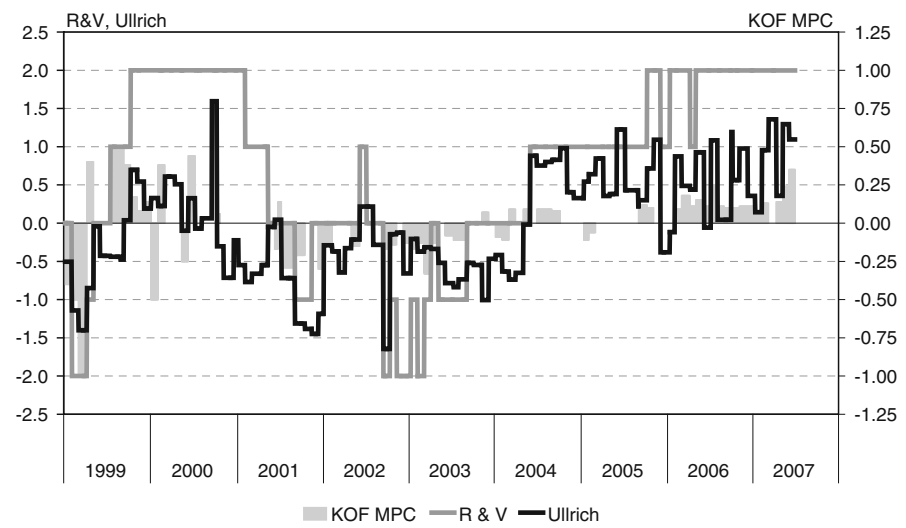

Fig. 2 The ECB communication indicators. Notes H\&U, BHS, R\&V and KOF MPC are the wording indicator of Heinemann and Ullrich (2007), the policy intention indicator of Berger et al. (2010), the updated Rosa and Verga (2007) indicator, and the KOF Monetary Policy Communicator as used by Conrad and Lamla (2007), respectively. Ullrich is the indicator of Ullrich (2008)

\section{Estimation results}

Table 2 shows our baseline model, i.e. the model without communication indicators and without the interbank rate. This model is first estimated with OLS as this allows transforming the estimated coefficients into the underlying structural parameters. All estimated coefficients are significant and have the expected sign. The structural parameters show that the results are in line with the so-called Taylor principle (i.e. $\beta>1$ ). According to the Taylor principle, if inflation increases the nominal interest rate must increase more (i.e. $\Delta i>\Delta \pi$ ) in order to raise the real rate. If this principle is violated, self-fulfilling bursts of inflation may be possible. The estimates also suggest that the MA(1) term is insignificant, i.e. $\delta=0$ (not shown).

As the ECB sets interest rates in steps and only discrete changes are observed, we prefer estimating ordered probit models. So in the remainder of the paper, all reported results refer to ordered probit estimates. The change in the main refinancing rate is transferred into a $(-1,0,1)$-dummy to reflect interest cuts, no 
Table 1 Correlation matrix

\begin{tabular}{|c|c|c|c|c|c|c|c|c|c|}
\hline & (1) & (2) & (3) & (4) & $(5)$ & (6) & (7) & (8) & (9) \\
\hline (1) MRR & & -0.08 & 0.41 & 0.62 & 0.16 & - & -0.15 & - & -0.05 \\
\hline (2) $\mathrm{IBR}_{t=C F}-\mathrm{MRR}$ & -0.08 & - & -0.21 & 0.32 & 0.32 & - & 0.26 & - & 0.06 \\
\hline (3) Inflation exp. & 0.56 & -0.25 & - & 0.02 & 0.28 & - & 0.18 & - & 0.18 \\
\hline (4) Growth exp. & 0.59 & 0.34 & 0.07 & - & 0.55 & - & 0.21 & - & 0.16 \\
\hline (5) $\mathrm{R} \& \mathrm{~V}$ & 0.30 & 0.36 & 0.12 & 0.76 & - & - & 0.68 & - & 0.48 \\
\hline (6) $\mathrm{H} \& \mathrm{U}$ & 0.26 & 0.29 & 0.16 & 0.70 & 0.75 & - & - & - & - \\
\hline (7) Ullrich & -0.06 & 0.31 & 0.07 & 0.42 & 0.62 & 0.70 & - & - & 0.39 \\
\hline (8) BHS & 0.32 & 0.40 & 0.17 & 0.78 & 0.88 & 0.79 & 0.61 & - & - \\
\hline (9) KOF MPC & -0.04 & 0.05 & 0.08 & 0.21 & 0.41 & 0.33 & 0.33 & 0.28 & - \\
\hline
\end{tabular}

The correlation coefficients reported in italics (lower-left triangle) use a fixed sample of 68 observations during the period 1999-2004. Each of the correlation coefficients reported in the upper-right part use the 96 observations, which cover the period from January 1999 until June 2007

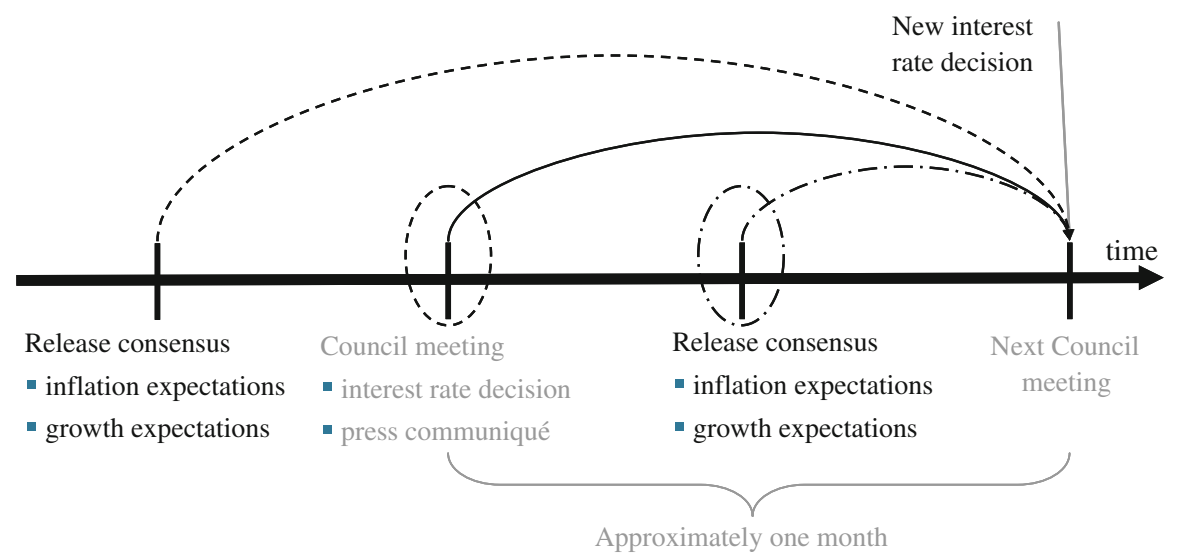

Fig. 3 The timing in our model

changes, and interest rate increases. ${ }^{14}$ The final column of Table 2 shows the ordered probit results for the baseline model. They are similar to the OLS estimates.

Tables 3 and 4 show the estimation results if we add the various ECB communication indicators. In each regression we use the maximum number of observations possible. However, the conclusions are the same if we restrict the sample to those 64 observations (basically the 1999-2004 period) for which all indicators are available (results are available on request). The difference between both tables is that in Table 4 also the one-month interbank rate is included as explanatory variable to control for financial markets forecast of future ECB monetary policy moves. If markets were efficient, all available information,

\footnotetext{
${ }^{14}$ This choice is motivated by the fact that only in a few cases the interest rate was moved by 50 basis points (in either direction). Hence, it is statistically difficult to distinguish between the case of a 25 and a 50 basis point move. The results do not change in any meaningful way in case we distinguish between 50 and 25 basis point changes.
} 
Table 2 Baseline model: OLS and ordered probit models

\begin{tabular}{|c|c|c|c|c|}
\hline & $\begin{array}{l}\text { OLS } \\
(1)\end{array}$ & & $\begin{array}{l}\text { Implied structural } \\
\text { parameters } \\
(2)\end{array}$ & $\begin{array}{l}\text { Ordered } \\
\text { Probit } \\
(3)\end{array}$ \\
\hline $\mathrm{MRR}_{t-1}$ & $\begin{array}{l}-0.109 * * * \\
(-3.53)\end{array}$ & $\rho$ & $\begin{array}{l}0.891 * * * \\
(28.96)\end{array}$ & $\begin{array}{l}-1.048 * * * \\
(-4.06)\end{array}$ \\
\hline Inflation $\exp _{\cdot t=C F}$ & $\begin{array}{l}0.154 * \\
(1.74)\end{array}$ & $\beta$ & $\begin{array}{l}1.414 * * \\
(2.12)\end{array}$ & $\begin{array}{l}1.700 * * \\
(2.50)\end{array}$ \\
\hline Growth $\exp \cdot t=C F$ & $\begin{array}{l}0.187 * * * \\
(4.18)\end{array}$ & $\gamma$ & $\begin{array}{l}1.725^{* * * *} \\
(6.35)\end{array}$ & $\begin{array}{l}1.756^{* * * *} \\
(4.93)\end{array}$ \\
\hline Constant & $\begin{array}{l}-0.381 * * \\
(-2.31)\end{array}$ & $r^{*}$ & $\begin{array}{l}0.766^{* * * *} \\
(5.25)\end{array}$ & \\
\hline Observations & 96 & & & 96 \\
\hline$R$-squared & 0.225 & & & \\
\hline Log likelihood & 47.97 & & & -54.20 \\
\hline
\end{tabular}

The sample uses all observations available during the period 1999-2007 (June). In columns (1) and (2) $t$-statistics are in parentheses. In column (3) robust $z$-statistics are in parentheses

$* * *, * *$ and $*$ indicate significance at the level of 1,5 and $10 \%$, respectively

including the ECB communication, should be reflected in asset prices. In that case, the ECB communication indicators should become insignificant.

Two conclusions can be drawn from our estimations. First, in line with the results of Heinemann and Ullrich (2007) and Rosa and Verga (2007), the coefficients of the ECB communication indicators are significantly different from zero, although in some cases only at the $10 \%$ level, except for the KOF MPC. However, according to the KOF MPC, the ECB already starts preparing the general public for interest rate changes more than 1 meeting in advance. Once it is lagged by one period, the KOF MPC turns significant, while the lag of the other indicators is not significant. Second, also if the interbank rate is included, the ECB communication indicators remain significant. The latter result implies that the interbank interest rate, although it is always significant, does not contain all the information provided by the communication indicators. Figures 4 and 5 show the implied probabilities of the estimates reported in Tables 3 and 4, respectively.

As both figures show, the estimated probabilities quite heavily depend upon these indicators. Estimates of the marginal effects confirm this. For instance, a one standard deviation increase in the value of the Rosa and Verga indicator (while keeping the other explanatory variables equal to their means) increases the probability of an interest rate hike by close to 13.5 percentage points.

As suggested by one of the referees, we have also estimated a slightly different model using different forecasting horizons.

$$
\begin{gathered}
i_{t+j}^{T}=(r *+\pi *)+\beta\left(E_{t} \pi_{t+12}-\pi *\right)+\gamma\left(E_{t} \Delta y_{t+12}-\Delta y *\right) . \\
\Delta i_{t+j}=(1-\rho)\left(i_{t+j}^{T}-i_{t-1}\right)+v_{t}, j=0,1,2,3 \\
j=0,1,2,3
\end{gathered}
$$




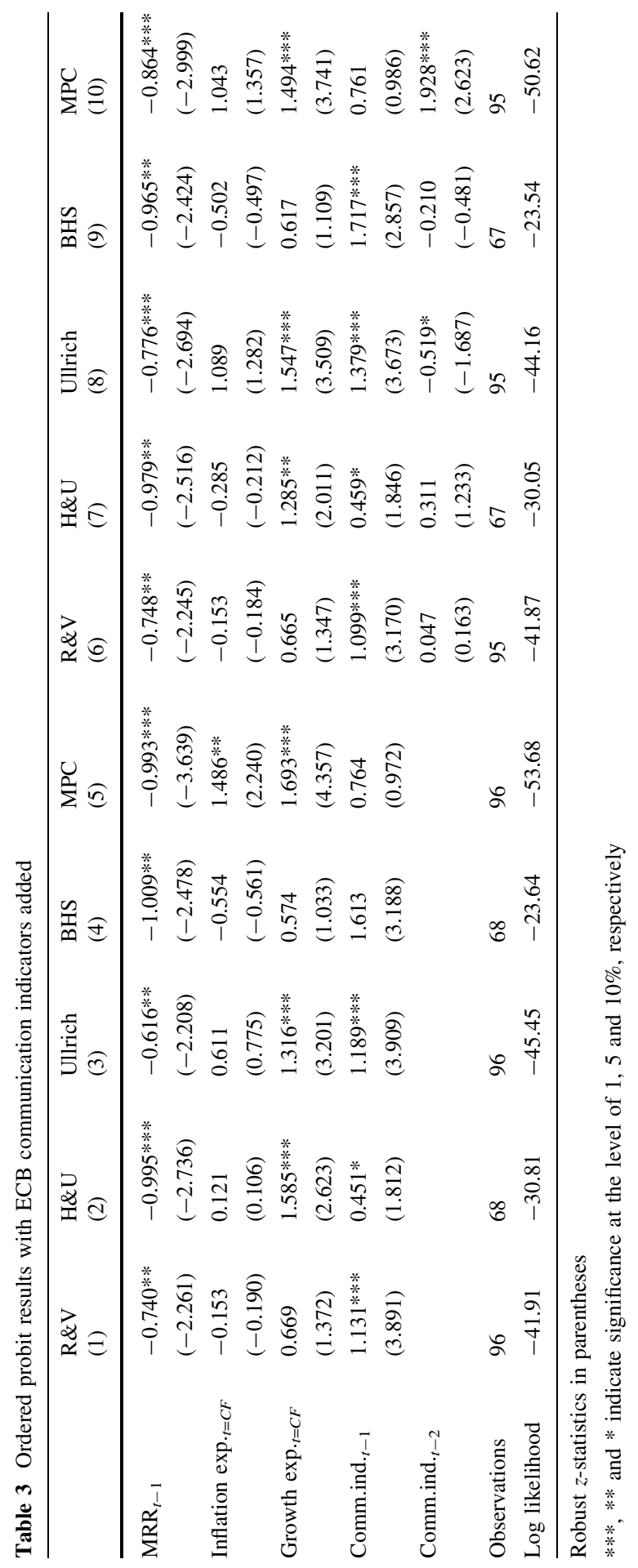




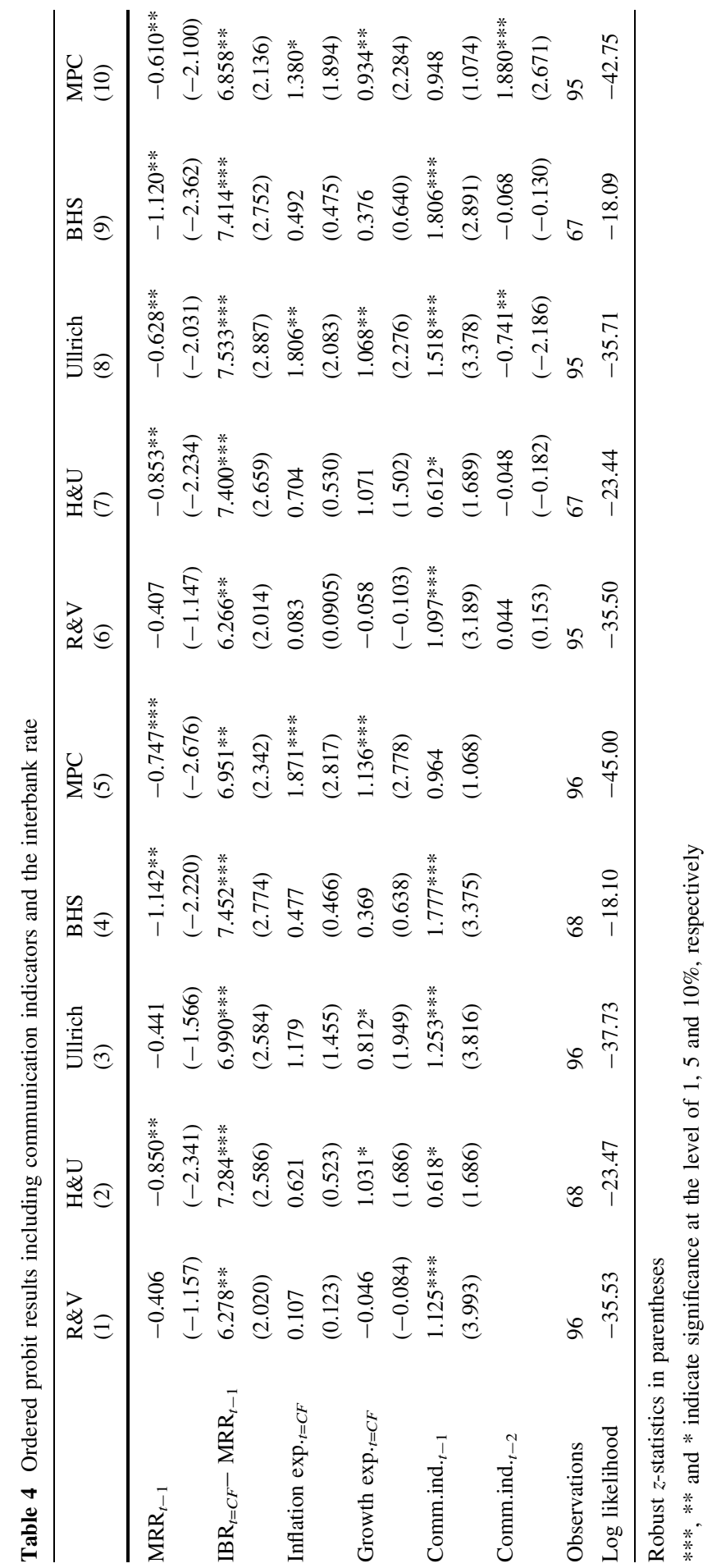



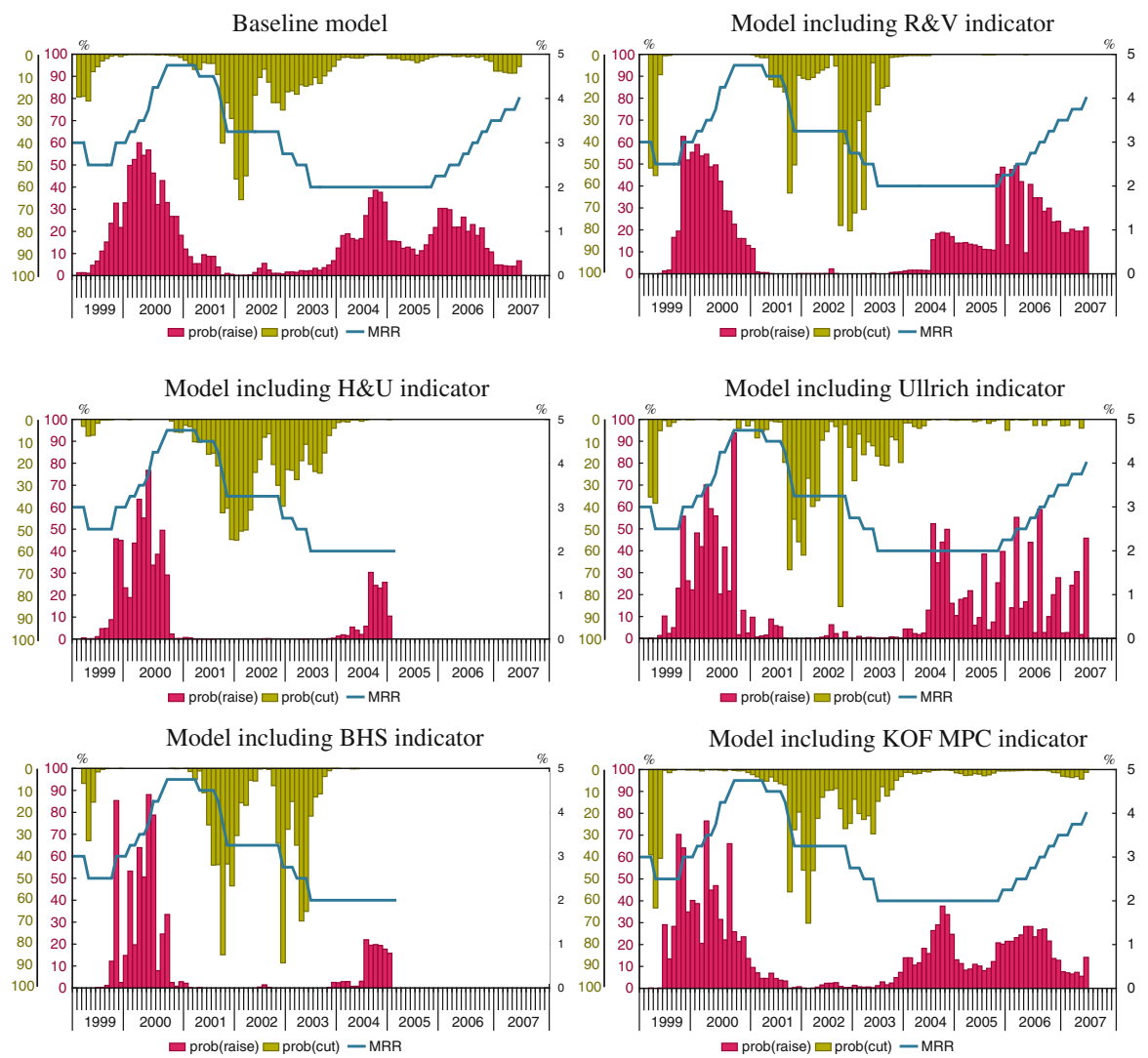

Fig. 4 Probability estimates. Notes The first figure does not include any communication indicators. The probabilities of the remaining figures are based upon the regressions reported in Table 3 and include both lags of the communication indicators

The results, shown in Table 5, suggest that the communication variables remain significant. In line with our previous findings, the KOF indicator only becomes significant if $j>0$.

Finally, Table 6 shows the results for out of sample forecasts for three indicators that are available for years after 2004. Starting with the first interest rate decision in 2005, a total of 29 real-time one-period-ahead forecasts were produced. For each forecast the model was re-estimated to ensure that all information available at that moment in time was optimally used. The table shows the so-called Brier score (QPS) and the ranked probability score (RPS). Following Boero et al. (2009), these measures can be explained as follows. The Brier score is calculated as:

$$
Q P S=\frac{1}{T} \sum_{t=1}^{T} \sum_{k=1}^{K}\left(p_{k t}-d_{k t}\right)^{2}
$$



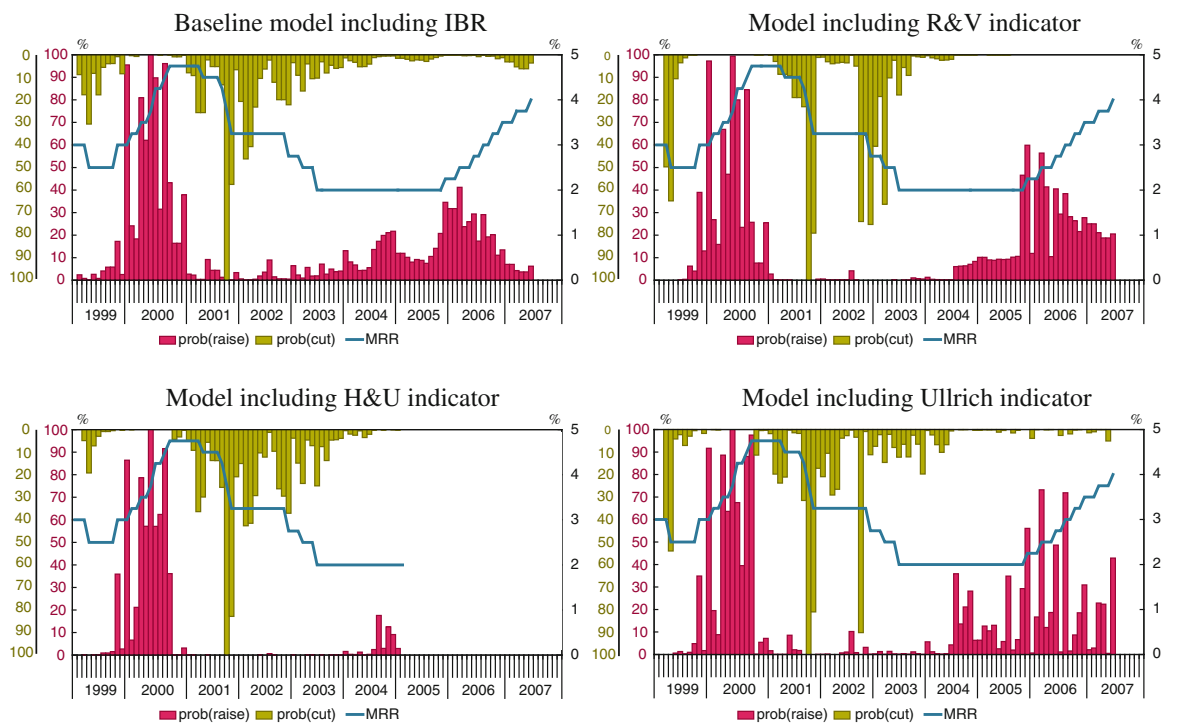

Model including BHS indicator
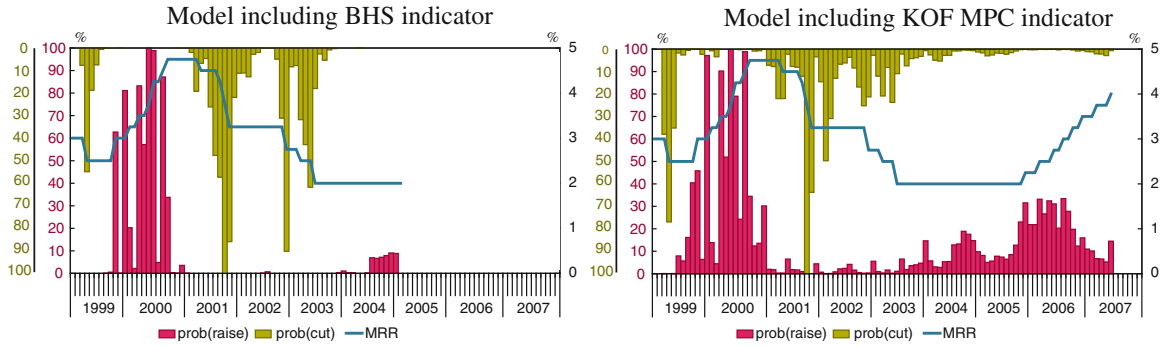

Fig. 5 Probability estimates including the interbank rate. Notes The first figure does not include any communication indicators. The probabilities of the remaining figures are based upon the regressions reported in Table 4 and include both lags of the communication indicators

where $p_{k t}$ is a probability forecast of the outcome $k$ (no change of the interest rate, an increase, or a decrease of the interest rate) at time $t$, while $d_{k t}, k=1, \ldots, K$, takes the value 1 if the outcome $x_{t}$ is $k$, while otherwise $d_{k t}=0$. The range of $Q P S$ is usually $0 \leq Q P S \leq 2$, where the lower bound corresponds to the best fit. The ranked probability score is calculated as:

$$
R P S=\frac{1}{T} \sum_{t=1}^{T} \sum_{k=1}^{K}\left(P_{k t}-D_{k t}\right)^{2}
$$

where $P_{k t}$ and $D_{k t}$ are the density functions of $p_{k t}$ and $d_{k t}$, respectively. The RPS penalizes forecasts less severely when their probabilities are close to the actual outcome, and more severely when their probabilities are further from the actual outcome. Like the Brier score, its minimum value is 0 . Its maximum value equals $K-1$.

The main conclusion following from Table 6 is that generally the quality of the forecasts improves in comparison to the base model when the ECB communication 


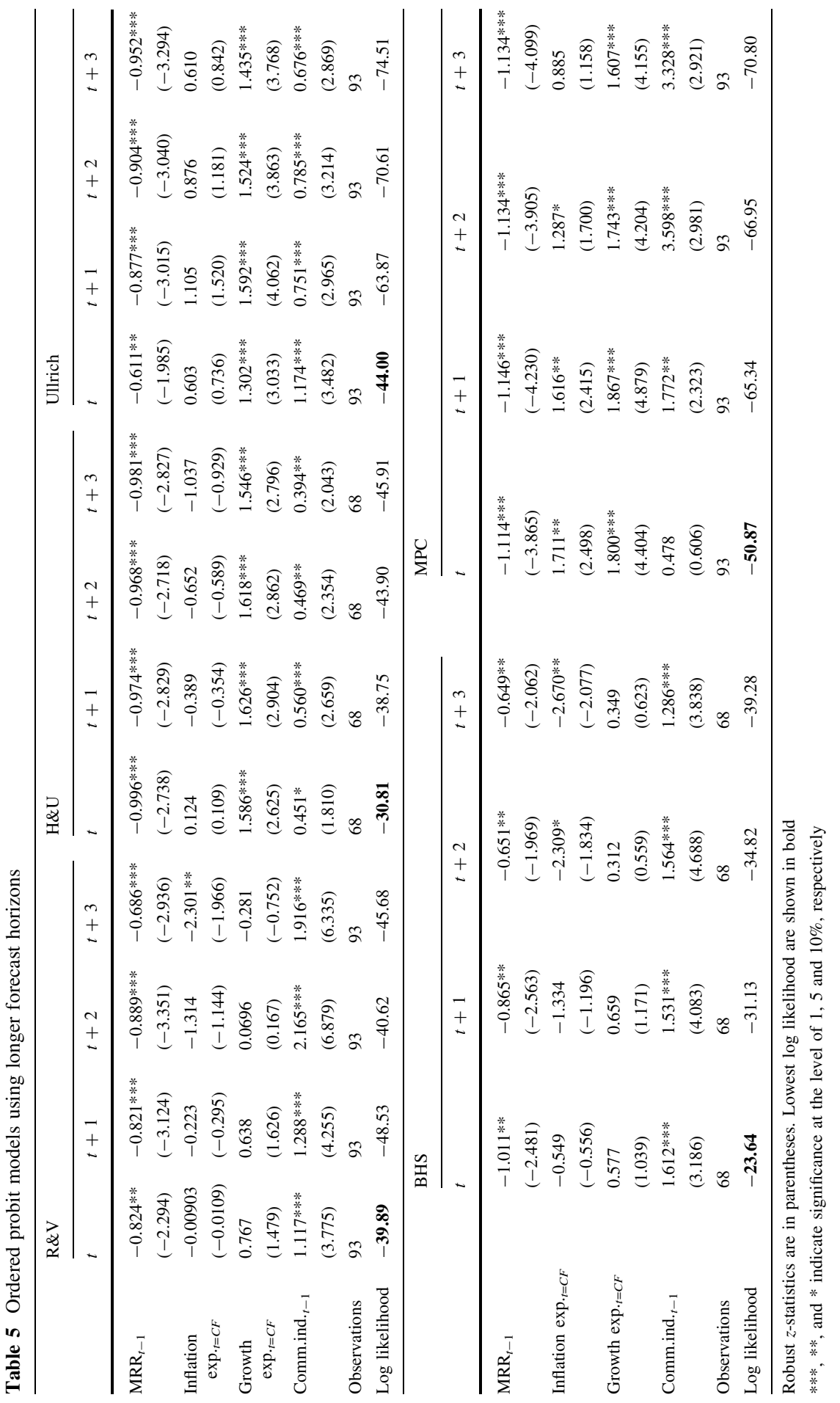


Table 6 Out-of-sample forecasting

\begin{tabular}{|c|c|c|c|c|}
\hline & \multicolumn{2}{|l|}{ QPS } & \multicolumn{2}{|l|}{ RPS } \\
\hline & Without IBR & Incl. IBR & Without IBR & Incl. IBR \\
\hline Base model & 0.466 & 0.453 & 0.239 & 0.230 \\
\hline \multicolumn{5}{|c|}{ Using one lag of the communication indicator } \\
\hline $\mathrm{R} \& \mathrm{~V}$ & 0.395 & 0.382 & 0.198 & 0.191 \\
\hline Ullrich & 0.393 & 0.375 & 0.197 & 0.188 \\
\hline KOF MPC & 0.465 & 0.452 & 0.237 & 0.228 \\
\hline \multicolumn{5}{|c|}{ Using two lags of the communication indicator } \\
\hline$R \& V$ & 0.399 & 0.388 & 0.199 & 0.194 \\
\hline Ullrich & 0.371 & 0.347 & 0.186 & 0.174 \\
\hline KOF MPC & 0.467 & 0.456 & 0.236 & 0.230 \\
\hline
\end{tabular}

Results are based upon 29 out-of-sample forecasts

measures are included in the model (both the QPS and RPS are closer to zero), thereby confirming our previous findings. Also in line with our previous findings is that the inclusion of the (non-lagged) KOF MPC measure of ECB communication does not improve upon the quality of the forecasts.

Our main result that inclusion of ECB communication indicators in most cases leads to better forecasts of ECB interest rate decisions also holds when the interbank interest rate is included in the model. In fact, compared to the model that only includes Taylor rule variables, the forecasting ability of the model that takes up the interbank interest rate is hardly better.

\section{Conclusions}

Does it pay to watch the lips of the ECB President in order to forecast the next policy decision of the ECB, or does it suffice to base a forecast on the most recent information regarding expected inflation and output? We examine whether ECB communication adds information compared to the information provided by a Taylor rule model in which expected inflation and output are used. We use five indicators of ECB communication that are all based on the ECB President's introductory statement at the press conference following an ECB policy meeting. Our results suggest that even though the indicators are sometimes quite different from one another, they add information that helps predicting the next policy decision of the ECB compared to the information provided by expected inflation and expected output growth. Furthermore, also when the interbank rate is included in our Taylor rule model, the ECB communication indicators remain significant. The latter result implies that the interbank interest rate does not contain all the information provided by the ECB communication indicators.

Acknowledgments We like to thank participants in seminars at the Kiel Institute for the World Economy, Bilkent University (Ankara), the Central Bank of Turkey, the conference on 'Central Bank Communication Decision-Making and Governance' at Wilfrid Laurier University (Waterloo), the 2009 
conferences of CESifo on Macro, Money and International Finance, the European Economic Association, the Verein für Socialpolitik, the Swiss Society of Economics and Statistics and the 2010 annual conference of the Bank of Korea as well as two referees for their very helpful comments on a previous version of the paper. The views expressed do not necessarily reflect the views of DNB.

Open Access This article is distributed under the terms of the Creative Commons Attribution Noncommercial License which permits any noncommercial use, distribution, and reproduction in any medium, provided the original author(s) and source are credited.

\section{References}

Berger, H., De Haan, J., \& Sturm, J.-E. (2010). Does money matter in the ECB strategy? New evidence based on ECB communication. International Journal of Economics and Finance. doi: 10.1002/ijfe.412.

Bernoth, K., \& von Hagen, J. (2004). The Euribor futures market: Efficiency and the impact of ECB policy announcements. International Finance, 7, 1-24.

Blinder, A. S., Michael, E., Fratzscher, M., De Haan, J., \& Jansen, D.-J. (2008). Central bank communication and monetary policy: A survey of theory and evidence. Journal of Economic Literature, 46(4), 910-945.

Boero, G., Smith, J., \& Wallis, K. F. (2009). Quadratic scoring rules and density forecast histograms. (Paper Presented at the Econometric Society Australasian Meeting), Canberra, July 2009.

Brand, C., Buncic, D., \& Turunen, J. (2006). The impact of ECB monetary policy decisions and communication on the yield curve. (ECB Working Paper 657).

Conrad, C., \& Lamla, M. J. (2007). The high-frequency response of the EUR-US dollar exchange rate to ECB monetary policy announcements. (KOF Working Paper 174).

De Haan, J. (2008). The effect of ECB communication on interest rates: An assessment. The Review of International Organizations, 3(4), 375-398.

Ehrmann, M., \& Fratzscher, M. (2007). Communication by central bank committee members: Different strategies, same effectiveness? Journal of Money, Credit and Banking, 39(2-3), 509-541.

Ehrmann, M., \& Fratzscher, M. (2009). Purdah-On the rationale for central bank silence around policy meetings. Journal of Money, Credit and Banking, 41(2-3), 517-528.

Gerberding, C., Worms, A., \& Seitz, F. (2005). How the Bundesbank really conducted monetary policy: An analysis based on real-time data. North American Journal of Economics and Finance, 16(3), 277-292.

Gerlach, S. (2007). Interest rate setting by the ECB, 1999-2006: Words and deeds. International Journal of Central Banking, 3, 1-45.

Gorter, J., Jacobs, J., \& De Haan, J. (2008). Taylor rules for the ECB using expectations data. Scandinavian Journal of Economics, 110(3), 473-488.

Heinemann, F., \& Ullrich, K. (2007). Does it pay to watch central bankers lips? The information content of ECB wording. Swiss Journal of Economics, 143(2), 155-185.

Jansen, D.-J., \& De Haan, J. (2009). Has ECB communication been helpful in predicting interest rate decisions? An evaluation of the early years of the Economic and Monetary Union. Applied Economics, 41(16), 1995-2003.

Kim, T.-H., Mizen, P., \& Chevapatrakul, T. (2008). Forecasting changes in UK interest rates. Journal of Forecasting, 27(1), 53-74.

Kohn, D. L., \& Sack, B. (2004). Central bank talk: Does it matter and why? In Macroeconomics, monetary policy, and financial stability. (pp. 175-206). Ottawa: Bank of Canada.

Musard-Gies, M. (2006). Do ECB's statements steer short-term and long-term interest rates in the eurozone? The Manchester School, 74(supplement), 116-139.

Orphanides, A. (2001). Monetary policy rules based on real-time data. American Economic Review, 91(4), 964-985.

Poole, W. (2001). Expectations. Federal Reserve Bank of St. Louis Review, 83(1), 1-10.

Rosa, C., \& Verga, G. (2007). On the consistency and effectiveness of central bank communication: Evidence from the ECB. European Journal of Political Economy, 23(1), 146-175. 
Rudebusch, G. D. (2002). Term structure evidence on interest rate smoothing and monetary policy inertia. Journal of Monetary Economics, 49(6), 1161-1187.

Sauer, S., \& Sturm, J.-E. (2007). Using Taylor rules to understand European Central Bank monetary policy. German Economic Review, 8(3), 375-398.

Svensson, L. E. O. (2003). What is wrong with Taylor rules? Using judgment in monetary policy through targeting rules. Journal of Economic Literature, 41(2), 427-477.

Taylor, J. B. (1993). Discretion versus policy rules in practice. Carnegie-Rochester Conference Series on Public Policy, 39, 195-214.

Ullrich, K. (2008). Inflation expectations of experts and ECB communication. North American Journal of Economics and Finance, 19(1), 93-108.

Walsh, C. E. (2004). Implications of a changing economic structure for the strategy of monetary policy. (UC Santa Cruz SCCIE Working Paper 03-18). 